International Journal of Engineering \& Technology, $7(2.7)(2018) 542-545$
International Journal of Engineering \& Technology
SPC
Website: www.sciencepubco.com/index.php/IJET
Research Paper

\title{
An Appraisal on Recurrent Pattern Analysis Algorithm from the Net Monitor Records
}

\author{
Sri Hari Nallamala ${ }^{1 *}$, Siva Kumar Pathuri² ${ }^{2}$ Dr. Suvarna Vani Koneru ${ }^{3}$ \\ ${ }^{1}$ Research Scholar, CSE Dept., K L E F (Deemed to be University), Vaddeswaram, Guntur, A.P. \\ ${ }^{2}$ Associate Professor, CSE Dept., K L E F (Deemed to be University), Vaddeswaram, Guntur, A.P. \\ ${ }^{3}$ Professor, CSE Dept., V.R. Siddhartha Engg. College, Vijayawada, Krishna Dist., A.P. \\ *Corresponding author E-mail: nallamala.srihari@gmail.com
}

\begin{abstract}
Web data mining is a rising examination territory where taking out information is an essential job and a range of algorithms has been projected with a specific end goal to comprehend the an assortment of issues identified with web mining from available dataset. Here, we focus Frequent Pattern-Growth algorithm for data mining. Concerning FP-Growth, the efficiency is insufficient since mining progression is depends on large tree-frame data structure by internal memory estimate. We focuses on server monitor documents to find web convention forms of websites using web utilization mining and in exacting spotlights. Here, we had the practice to work with the projected strategy which could conceivable to eradicate the disadvantage of restriction of the presented rehearse in the area of web mining. An assortment of web usage mining practice can advance effort on numerous areas of scientific, medical \& social media applications to advance toward for the research \& security united zone. A briefed outline development system could help in gathering additional information on utilizing line up algorithm which shows the information state-plans effectually.
\end{abstract}

Keywords: Clustering; Data Mining; Ranking; Web Logs; Web Mining.

\section{Introduction}

The data consolidation assembled by conventional data mining procedures and strategies with in arrangement accumulated in excess of the WWW [2] is known as Web mining. This is utilized to know the client deeds, assess proficiency of a fastidious website, and aid enumerates the achievement of the marketing promotion. Content mining is utilized to examine information generated by web spiders and research engines. Configuration mining was utilized to investigate data correlated about configuration of a specific web-site \& web-usage mining is useful to numerous genuine inconveniences to find captivating user routing patterns for upgrade of web proposal by building supplementary subject or suggestion perceiving user or user behavior.

These are known as data of web-server, relevance data of server \& submission level data. Data of web-server convey to the user logs that are formed at web-server. A portion of the archetypal information made at web-server includes page references, IP add., admission time of the user or client and also it is the major contribution to the recent researches.

We focus on web usage mining and in fastidious concentrates the server monitor records to find the web usage patterns of sites.

\section{Pattern Discovery - Phases in Web Mining}

\section{Data Preprocessing}

To get better signs of improvement the skill and comfort of the mining movement, the records must be preprocessed. Here, we snip dirty as well as improper data, to condense data capacity for detection of patterns part. Algorithms of field mining, data cleaning analyze the web $\log$ procedures dealing about the fields \& destruction.

\section{Patterns Detection}

Scarcely any methods to decide designs from preprocessed data are planned like clustering, sequential patterns, changing over IP addresses to province names, decision trees, sifting, dynamic site examination, path analysis, cookies, collusion rules, and more.

\section{Pattern Exploration}

Analysis like the consistency of calls per manuscript, mainly current vacation per record, who is staying which accreditations, recurrence of utilization of every hyperlink, and mostly late utilization of each hyperlink. The following frequent technique methods are utilized for pattern analysis: disclosure methods, OLAP strategy practices, Data and Knowledge Probing, Usability Exploration. 


\section{Review of Literature}

\section{Hao Yan,Bo Zhang,Yibo Zhang,Fang-2010.}

The WUM procedure extort behavioral designs as of the Internet exercise facts and, if existing, from the web-site in arrangement \& on the web-site clients. Now, we get two impressive assistance for Web Usage Mining progression. The writer proposes a custombuilt submission particular system for preprocessing of web logs and an altered regular outline tree to discover the patterns professionally.

\section{Huiping Peng-2010.}

Given the framework analysis stage fascinating knowledge is extract from repeated patterns and these outcomes are utilized for site changes. We utilize FP-Growth technique to acquire recurrent admittance patterns, give profitable data which is almost the client's attentiveness.

\section{Min Chen,Young U.Ryu-2011.}

Giving awareness about to progress one site without presenting liberal variations. Expressly, we mean an accurate preparing sculpt to propel the user directing on site however limit change to its current configuration. Outcomes since across the board tests steered on a responsively reachable real open dataset assign that our sculpt not just broadly enhances the client guiding among very limited amend, but moreover in addition could productively settled.

\section{Joy Shalom Sona,AshaAmbhaikar-2012.}

Exhibits wide-ranging outline of web-mining methods, strategies utilized for the assessment of merging structures to attain superior web controlling proficiency with a specific end goal to enhance the viability of site. It amalgamates and arranges among various explanations behind making proposal including recurrence of passageway, and examples of admittance by organization to the site.

Table 1: Related Algorithms with their Advantages and Disadvantages

\begin{tabular}{|c|c|c|c|}
\hline $\begin{array}{l}\text { Algorithms } \\
\text { Storage }\end{array}$ & Structure & Advantages & Disadvantages \\
\hline Aprion' & $\begin{array}{l}\text { Array } \\
\text { based }\end{array}$ & $\begin{array}{l}\text { Any subset of repeated item } \\
\text { set is also frequent } \\
\text { Item set. }\end{array}$ & $\begin{array}{c}\text { Various scans have to be } \\
\text { done on database. Its time } \\
\text { and Memory complication } \\
\text { is very large. }\end{array}$ \\
\hline Aprion Tid & $\begin{array}{l}\text { Array } \\
\text { based }\end{array}$ & $\begin{array}{l}\text { Number of entries may be } \\
\text { smaller than the number } \\
\text { of communication } \\
\text { in the data base. }\end{array}$ & $\begin{array}{c}\text { The time and Space } \\
\text { complexity is also very } \\
\text { outsized }\end{array}$ \\
\hline FP tree & Tree based & $\begin{array}{c}\text { Scans the database only } \\
\text { twice. It has interactive rule } \\
\text { mining }\end{array}$ & $\begin{array}{l}\text { It seems to be difficult in } \\
\text { incremental. It require } \\
\text { less memory and more } \\
\text { execution time }\end{array}$ \\
\hline $\begin{array}{c}\text { Custom } \\
\text { built Aprioni }\end{array}$ & $\begin{array}{l}\text { Array } \\
\text { Based }\end{array}$ & $\begin{array}{l}\text { Based on old Aprion } \\
\text { algonithm. It is efficient and } \\
\text { effective pattem analysis. }\end{array}$ & $\begin{array}{l}\text { It requires more memory } \\
\text { and more execution time. }\end{array}$ \\
\hline $\begin{array}{l}\text { FAP(frequent } \\
\text { access pattem) }\end{array}$ & Tree Based & $\begin{array}{l}\text { constructs frequent access } \\
\text { pattem tree (FAP tree) as } \\
\text { per the access paths and } \\
\text { Next step is where the } \\
\text { function of FAP-growth is } \\
\text { used to mine both long } \\
\text { and short access pattems on } \\
\text { the FAP tree }\end{array}$ & $\begin{array}{l}\text { No sequence among the } \\
\text { elements in the data. }\end{array}$ \\
\hline
\end{tabular}

\section{Problem Invention}

Nowadays the WWW or Internet was accepted and intelligent moderate to designate informative data. The web is gigantic, various, mighty plus shapeless behaviour of web data, web data exploration look into experience parcel of difficulties for web mining. Evidence user could experience subsequent difficulties while cooperating through web.

3.1. Verdict noteworthy Data - Individuals either peruse or utilize the investigation benefit when they need to discover particular in arrangement on the web. The present pursuit devices have tribulations like low exactness which is because of unimportance of huge numbers of the list items. These outcomes in a trouble in finding the fitting data. Another bind is low review which is because of absence of capacity to file all the in grouping accessible over web.

3.2. Create novel awareness about arrangement accessible over web-this quandary is essentially associate issue of the beyond issue. On top of issue is question provoke procedure (recovery situated) however this difficulty is information trigger procedure that trust that as of now has assemblage of web information and concentrate possibly valuable colleague out of it.

3.3. Personalization of data - Once individuals blend by the web they change in the substance and introductions they incline toward.

3.4. Knowledge around customers or separable users - This issue is about what the client does and needs. Along with these issues there are sub scrape, for example, tweaking the data to the foreseen customers or even to customize it to identity client, issue identified with web composition and organization and promoting.

\section{Proposed Work}

Here we proposing an execution based on examination of before performed take a shot at the mining web dataset. Keeping in mind the end goal to locate a huge data about the regular dataset here system intend to play out the semantic \& synaptic pursuit on ruling the right data. In this manner it will play out the abnormal state structure specialist built semantic \& synaptic find to locate the operational dataset from the web with the end goal that could be more serviceable to web consequences \& web-explore in web-data mining procedure.

\subsection{Synaptic Web}

The technique, synaptic web-mining which takes a shot at the undergrowth of neuron built records incisive \& custom practice, a synaptic web-mining influence evident of work to section together through connection which are aligned by flow coupled connection and more on, synaptic mining utilized, wherever a web look was essential to get particular outcome through accessible web dataset.

Consider the following as technical parameters -

1. Re-call.

2. Accuracy

3. Precision 


\section{Methodology of Work}

Here we quickly depict a strategy to found frequent (or) recurrent item pattern.

\subsection{Semantic Mining}

An web-mining from linger behind is ready in the former place, procedure mine the information which is web based and comparable to sort of question \& their accessibility in a semantic way, the information to be concentrate as well as practice to make Entropy.

\section{Synaptic Mining}

During our proposed system, patterns are classified as indicated by the span achieve over lattice model. Patterns may convert a lattice foundation over pattern span \& frequency of patterns.

Lattice Erection: An atom i.e. single page was the basic component of the lattice. Every page or atom remains for length-1 prefix consistency class. Since base components frequency of superior components by length $n$ could compute as utilizing two $n-1$ span patterns fitting to the similar group.

\subsection{Relating streak over Mined Data \& Entropy}

The outcome down to earth from the different semantic information and user can streamline as indicated by the representation. Line-up is an execution which gives a technique to the positioning advancement of information which gives the post ranking estimation and positioning utilizing diverse traits, which give repositioning of information utilizing Line up strategy. Genera procedure of approach is given in the diagram underneath to make clear the work stream of our expected design engineering.

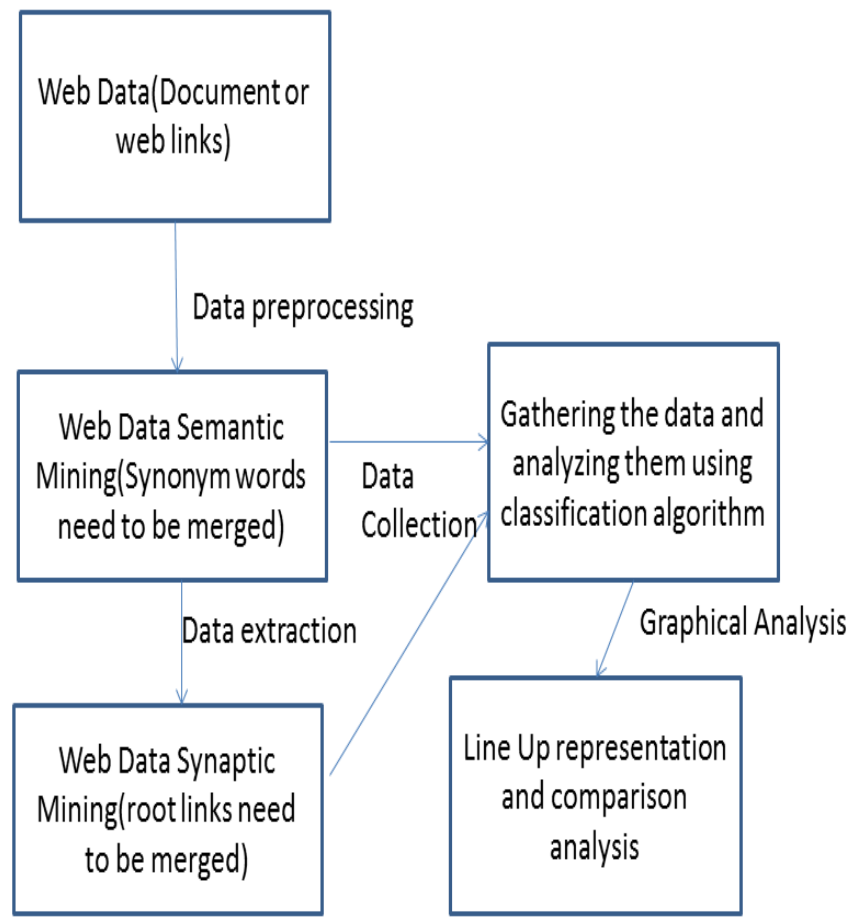

Fig 1: Flow of Methodology

\section{Expected Outcomes}

Our proposal had analysed mining by diverse outlines combined by frequent (or) recurrent item set through different web-logs \& data, now execution accomplish usage and subsequent outcomes stay normal, thought to be endless supply of suggested work algorithm.

- Implementation division time: Now, this proposal might want to investigate the implementation time of method while preparing the similar dataset contrast and the current present algorithm.

- Accuracy: Quantity of results relies upon the projected and current framework must be contrasted and graphical \& tabular format in normal results over foreseen work.

- Pattern quantity \& division must execute in the lead of projected effort achievement.

\section{Conclusion}

The methodology took after is novel \& two method based calculation which can practice data proficiently, also it would locate finest arrangement over patterns acknowledgement. The novel method needs absolute least rehashed database examines for frequent pattern-mining in web-usage mining. It diminishes the time $\&$ also space affecting. Web-usage mining was the significance of datamining practices to find usage-patterns from web-data, with a definite end goal to grasp and also better serve the requirements of web-based relevance. Here, another new method was projected to find the web-usage patterns of web-sites from server-log records through establishment of enhanced clustering. A powerful algorithm will be projected along with enhancements and in addition the achievement of web-mining methodology \& apriori algorithm. This anticipated advance over exploration job might be to plan the enhanced variant of apriori algorithm which should be acknowledge on Association Rule Mining of Server Log Files.

\section{Acknowledgement}

This research paper was supported by Dept. of CSE, K L E F (Deemed to be University). I thankful to my Internal Supervisor Sri. Siva Kumar Pathuri, Associate Professor, Dept. of CSE of K L E F (Deemed to be University) \& External Supervisor Dr. Suvarna Vani Koneru, Professor, Dept. of CSE of V.R. Siddhartha Engineering College who provided their insight and expertise that greatly assisted the research and also their comments that greatly improved the manuscript.

\section{References}

[1] Hao Yan, Bo Zhang, Yibo Zhang, Fang Liu, Zhenming Lei "Web usage mining based on WAN users behaviours" 2010.

[2] Huiping Peng "Discovery of Interesting Association Rules Based on Web Usage Mining" 2010.

[3] Iqbal Gondal and Joarder Kamruzzaman Md. Mamunur Rashid, "Mining Associated Sensor Pattern for data stream oorks" Spain, 2013.

[4] Joy Shalom Sona, AshaAmbhaikar "Reconciling the Website Structure to Improve the Web Navigation Efficiency" July 2012.

[5] K. R. Suneetha, Dr. R. Krishnamoorthi, "Identifying User Behaviour by Analyzing Web Server Access log" 2009

[6] Luca Cagliero and Paolo Garza "Infrequent Weighted Itemset Mining using Frequent Pattern Growth", IEEE Transactions on Knowledge and Data Engineering, 2013.

[7] Min Chen and young U. Ryu "Facilitating Effective User Navigation through Website Structure Improvement" IEEE KDD, 2011

[8] MADHAV, B.T.P., MOHAN REDDY, S.S., SHARMA, N., RAVINDRANATH CHOWDARY, J., PAVITHRA, B.R., KISHORE, K.N.V.S., SRIRAM, G. and SACHIN KUMAR, B., 2013. Performance characterization of radial stub microstrip 
bow-tie antenna. International Journal of Engineering and Technology, 5(2), pp. 760-764

[9] KISHORE, P.V.V., KISHORE, S.R.C. and PRASAD, M.V.D. 2013. Conglomeration of hand shapes and texture information for recognizing gestures of indian sign language using feed forward neural networks. International Journal of Engineering and Technology, 5(5), pp. 3742-3756.

[10] KISHORE, P.V.V., SASTRY, A.S.C.S. and KARTHEEK, A. 2014. Visual-verbal machine interpreter for sign language recognition under versatile video backgrounds, 1st International Conference on Networks and Soft Computing, ICNSC 2014 - Proceedings 2014, pp. 135-140.

[11] KISHORE, P.V.V., PRASAD, M.V.D., PRASAD, C.R. and RAHUL, R., 2015. 4-Camera model for sign language recognition using elliptical fourier descriptors and ANN, International Conference on Signal Processing and Communication Engineering Systems - Proceedings of SPACES 2015, in Association with IEEE 2015, pp. 34-38.

[12] Vudatha, C.P., Nalliboena, S., Jammalamadaka, S.K.R., Duvvuri, B.K.K., Reddy, L.S.S., Automated generation of test cases from output domain of an embedded system using Genetic algorithms, ICECT 2011 - 2011 3rd International Conference on Electronics Computer

Technology 5,5941989, pp. 216-220

[13] Sastry, J.K.R., Ganesh, J.V., Bhanu, J.S., I2C based networking for implementing heterogeneous microcontroller based distributed embedded systems, Indian Journal of Science and Technology, Volume 8, Issue 15, 2015 